\title{
Solución del caso. Abdomen agudo y la regla del dos
}

\section{Viene de la pagina 93}

\section{Solución del caso clínico}

El divertículo de Meckel es la anomalía congénita más común del tracto gastrointestinal y se produce debido a la persistencia del conducto onfalomesentérico. ${ }^{1}$

Comúnmente se hace referencia al divertículo de Meckel con la regla de los 2: ocurre en el 2\% de la población, con una relación hombre/mujer 2:1, se localiza frecuentemente a 2 pies $(60 \mathrm{~cm})$ de la válvula ileocecal, en el borde antimesentérico, midiendo usualmente $2 \mathrm{~cm}$ de diámetro y 2 pulgadas $(5 \mathrm{~cm})$ de longitud, puede contener 2 tipos de tejido ectópico (gástrico y pancreático) y es más habitual antes de los 2 años de edad. ${ }^{2}$

En el adulto presenta dos complicaciones principales: la obstrucción intestinal (40\%), seguida por la diverticulitis $(20 \%){ }^{3}$

En la TC del presente caso se observa aumento de la densidad grasa omental sobre el hipocondrio derecho y región umbilical asociado a una imagen redondeada que contiene una burbuja aérea en su interior y múltiples imágenes ganglionares a nivel de retroperitoneo y raíz del mesenterio (Figuras 1, 2 y 3).

Dados los hallazgos de las imágenes se llegó al diagnóstico de divertículo de Meckel complicado con diverticulitis, el cual fue confirmado por cirugía y estudio anatomopatológico posterior.

La TC es la modalidad de elección para el diagnóstico preoperatorio, considerando como clave diagnostica el punto de unión del divertículo al íleon distal. ${ }^{4}$

\section{Referencias}

1. Madhyastha S, Prabhu VL, Saralaya V, Prakash. Meckel's diverticulum: A case report. Int J Morphol 2007; 25: 519-522.

2. Uppal K, Tubbs RS, Matusz P, Shaffer K, Loukas M. Meckel's diverticulum: a review. Clinical Anatomy 2011; 24: 416-422.

3. Federle MP. Diagnosting Imaging-Abdomen, Meckel's diverticulum. Spain 2001: 367-369.

4. Elsayes KM, Menias CO, Harvin HJ, Francis IR. Imaging Manifestations of Meckel's Diverticulum. American Journal of Roentgenology 2007; 189: 81-88. 